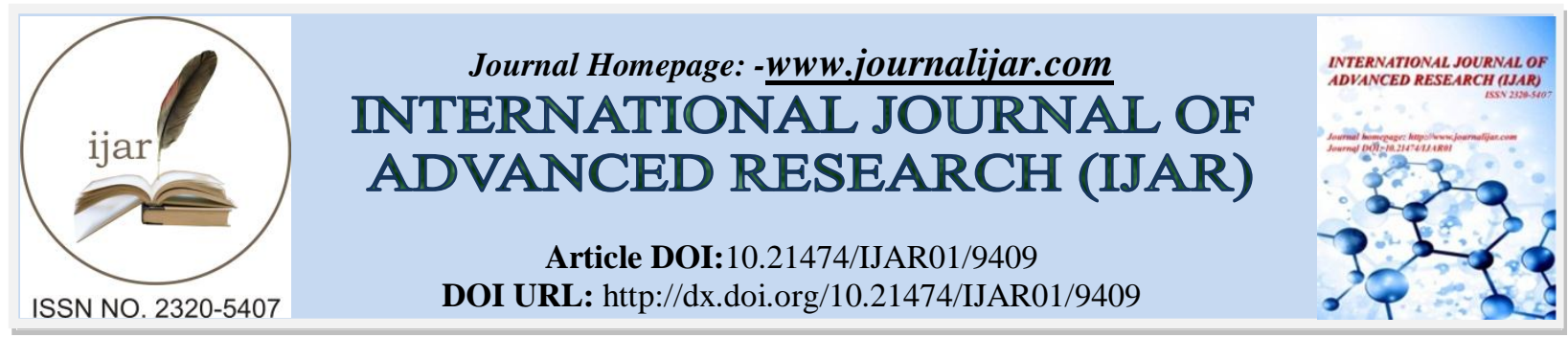

RESEARCH ARTICLE

\title{
PURIFICATION TECHNOLOGY AND SELECTION CRITERIA FOR WASTE WATER TREATMENT; A REVIEW.
}

Dr. Renu Nayar.

Department of chemistry D.P.Vipra P.G.college,Bilaspur C.G.

\section{Manuscript Info}

\section{Manuscript History}

Received: 20 May 2019

Final Accepted: 22 June 2019

Published: July 2019

\section{Key words:-}

Wastewater treatment, Contamination, Organic and Inorganic Pollutants, Ion exchange and Adsorption.

\section{Abstract}

This paper presents different methods for water purification and selecting the best techniques of wastewater treatment. Contamination word indicates pollution. It makes water completely unfit for the use of drinking. The accepted goals of the treatment are to remove unwanted constituents in the water and to make it safe to drinking or fit for domestic usage, but water purification may also be designed for a variety of other purposes, including fulfilling the requirements of medical, pharmacological, chemical and industrial applications. In this paper, a practical approaches are presented for selecting the wastewater treatment process based on the organic and inorganic pollutants present on surface water. The aim of this review of wastewater treatment is the protection of the environment in a manner commensurate with public health and socio-economic concerns. Understanding the nature of wastewater is fundamental to design an appropriate treatment technology in order to ensure the safety, efficacy and the quality of the treated wastewater. Further, improved public education to ensure awareness of the technology and its benefits, both environmental and economic, is recommended. The utility of any water recycling technique at a commercial level depends on the cost of construction, maintenance and operation. Taking all these points into consideration, ion exchange and adsorption is the best and most universal technique as it is used for the removal of a wide variety of organic and inorganic pollutants. It is also a rapid process with a low cost.

In this review, we present a summary of advance technologies for water purification and its application. The source of pollutants and impurities present in water are first introduced, and then the primary secondary and tertiary treatment process for removing various water pollutants, such as salt, metallic ions, anions, nanoparticles, organic chemicals, and biological substrates, are discussed. In addition, this work will be valuable for readers to understand the design and fabrication of various nonporous membranes, and their potential purification mechanisms towards different water pollutants. 


\section{Introduction:-}

Pollution of water bodies is increasing steadily due to rapid population growth, industrial proliferations, urbanizations increasing living standards and wide spheres of human activities. There is a difference between pollution of water and contamination of water. Groundwater is one of the most important natural resources. It is a major source of fresh drinking water in both the rural and urban regions (Gursimran Singhet.et al).Contamination term used to indicate pollution. It makes water totally unfit for the best use like drinking. Contamination makes water unsafe and unreliable for use. The polluted water is objectionable to human senses of sight odour, feel and taste, but contaminated waters is not expected to be apparently objectionable. Natural processes bringing the decomposed vegetables, animals and weathered products into main water resources. All these processes are interdependent to each other and lead to deterioration of natural environment. If organic waste is added to water, it will not only influence the chemical characteristics, but will also affect colour, odour and biological properties of water. Some anthropogenic processes like industrial, agricultural, urban, domestic, radioactive, mining sources, use of pesticides and fertilizers by man, which are constantly poured in water deteriorating it to such an extent that it becomes unfit for living communities. (Sadhana churassia et al)

Given the importance of clean water to human health and economic growth, and the serious scarcity of water in developing countries, exploring the water purification market could be a potential business opportunity for private investors or corporations. This paper evaluates the economic feasibility of providing water purification technologies in rural and urban areas of developing countries, along with practical considerations of social and political factors that may affect market entrance strategy. (Vigneswaran S.et al).

Purifying water may reduce the concentration of particulate matter including suspended particles, parasites, bacteria, algae, viruses, fungi, as well as reducing the concentration of a range of dissolved and particulate matter. Water purification is the way of removing undesirable chemicals, biological contaminants, total dissolve solids, suspended solids, calcium ions, magnesium ions and gases from water. All water purification technologies are not suitable for use in remote areas, In the present article some important and advance method for selecting for rural and urban areas. (Michelle Thompson).

In this review, several of these commercially available on-site water filtration technologies are assessed based on the some important factors such as effectiveness, energy consumption, waste generated and environmental impacts

\section{Aim of the study}

In the present paper the aim of the study is to review the technologies for making water fit for a specific purpose. The accepted goals of the treatment are to remove unwanted constituents in the water and to make it safe to drinking or fit for domestic usage, but water purification may also be designed for a variety of other purposes, including fulfilling the requirements of medical, pharmacological, chemical and industrial applications. The methods used include physical processes such as filtration, sedimentation, and distillation; biological processes such as slow sand filters or biologically active carbon; chemical processes such as adsorption ion exchange ,electro coagulation, membrane, flocculation, chlorination and the use of electromagnetic radiation such as ultraviolet light.

Sources of Chemical impurities in water 


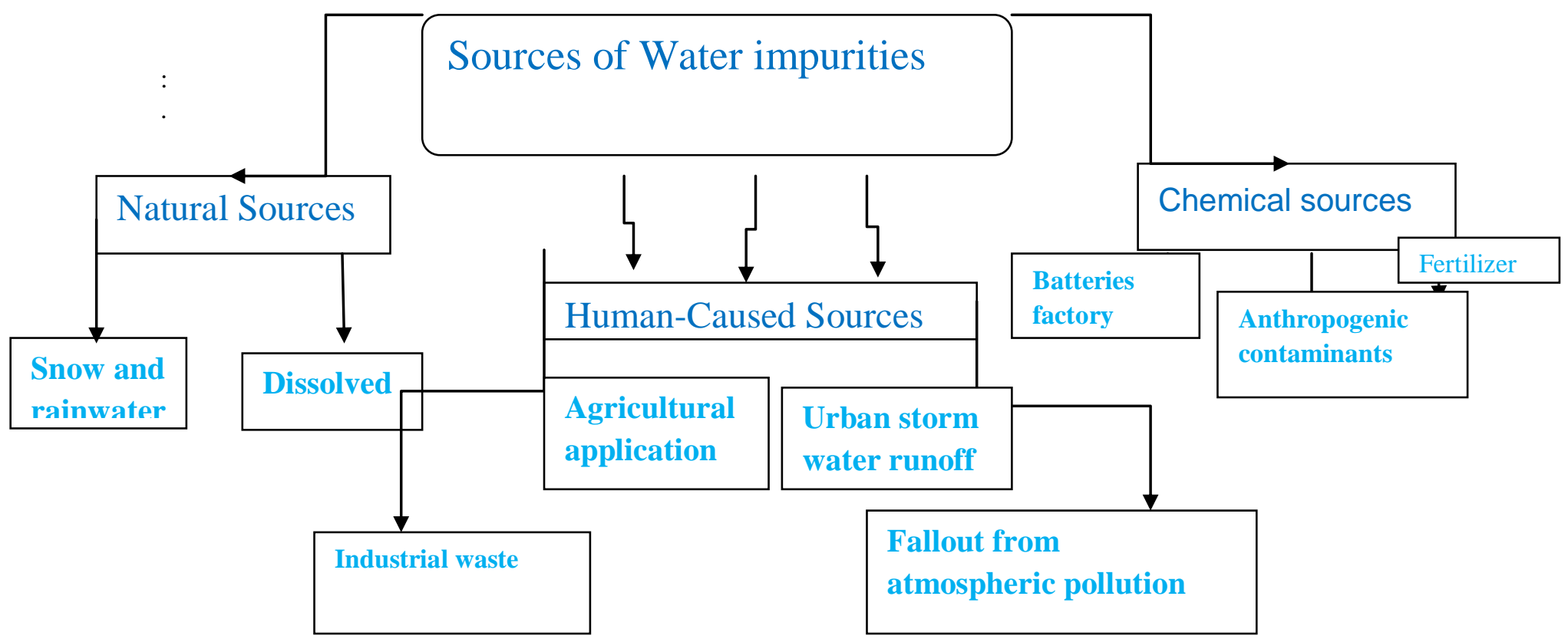

Snow and rainwater contain dissolved and particulate minerals collected from atmospheric particulate matter and a small amount gases dissolved from atmospheric gases. Snow and rainwater have virtually no bacterial content until they reach the surface of the earth.

After precipitation it reaches the surface of the earth and flows over and through the soil, there are innumerable opportunities for introduction of mineral, organic, and biological substances into water. Water can dissolve at least a little of nearly anything it contacts from the atmosphere and soil. Because of its relatively high density, water can also transport suspended solid. Even under pristine conditions, surface and ground-water will usually contain various dissolved and suspended chemical substances. Many human activities such as Petroleum leaks and spill ,Urban storm water runoff, Leachate from landfill, septic tanks, treatment lagoons and mine tailing etc cause additional possibilities for water contamination. Acids the waste product of some industries such as batteries factory, explosive factory contains acids. If these waste products directly discharge into the water bodies then it will be harmful for life. Fertilizer industries contains certain inorganic compounds such as sulphides nitrates phosphates and ammoniate which are harmful for life organic compounds may exist in water due to presence of fats proteins and carbohydrates. Organic compounds stemming from agricultural and domestic industrial waste are known as anthropogenic contaminants.

\section{Various Impurities present in water}

Water is the world's most precious resource. However, it is not exempt from certain impurities that can severely affect clean consumption. These impurities include dust, fine sand, clay, dirt, and biological contaminants .Pure water is tasteless, colorless and odorless, but water from rainfall, streams and wells is known to harbor harsh chemicals and elements, including acid and metallic rust elements. Similarly, many drinking water systems also contain chlorine, as well as high levels of calcium. The following common contaminants in water fall into seven major categories: 


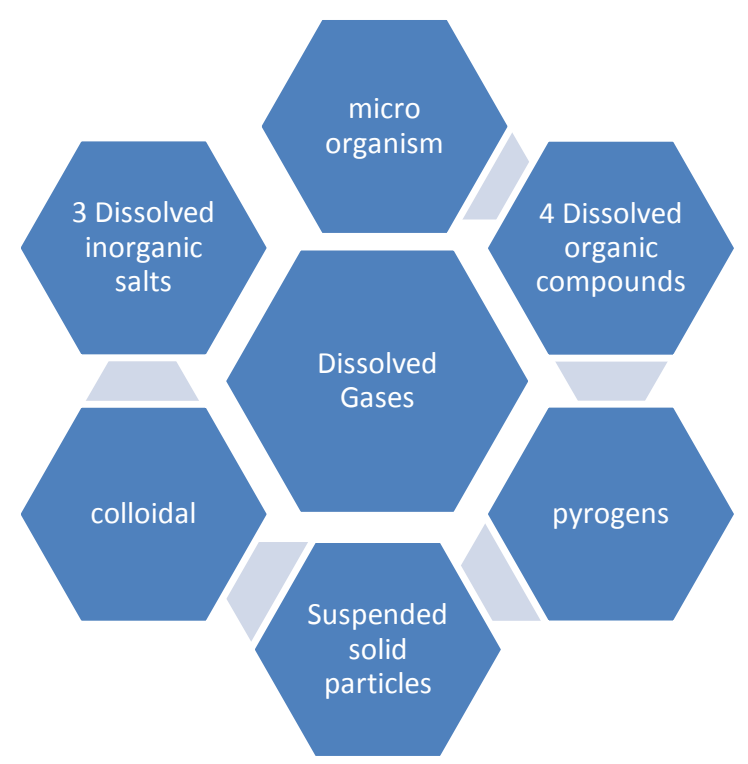

\section{Suspended solid particles and Colloids}

These are the solids which are insoluble like dust, rotten leaves, fine sand, clay, rust, etc. They remain suspended in the water and cause muddy water or cloudiness in water. Total suspended solids are particles that are larger than 2 microns found in the water body. Anything smaller than 2 microns is considered a dissolved solid. Silt and pipe work debris cause cloudiness in the water. It is known as turbidity which measures the light scattering effect of the particles. Suspended solids concentration is usually expressed in milligrams per liter which is the equal of parts per million (ppm).Organic wastage which is biodegradable and comes from either plants and animals are usually broken down by other organisms. Organic waste are made up of vegetables and fruit debris paper bones and human waste as a colloidal impurities are present in water bodies. This problem occurs due to contact with suspended matter and elements like sand, rocks and organic matter flowing in pond, streams and lakes that renders water undrinkable or non-pure.

\section{Dissolved inorganic salts, organic matter and dissolved gases}

Dissolved inorganic substances are measured as total dissolved solids (TDS) in Water body. There were a wide range of different salts commonly found in water which come from a variety of sources, some natural and some of human activity. Higher concentrations of ions conduct more electricity than low concentrations, thus high conductivity indicates high salt contamination.

Many different organic solids are found in water, in the from animal and vegetable decay and human activity such as animal husbandry, domestic waste, industrial waste etc. They can include proteins, chloramines, alcohols, aldehydes, ketones and the organic residues from detergents, pesticides and herbicides. And some organic waste from the realm of the kitchen include like egg shells and vegetable and fruit peels like orange rinds, apple skins, tomatoes, and cucumber skins.

Carbon dioxide readily dissolves in water to form weakly acidic carbonic acid, $\mathrm{H}_{2} \mathrm{CO}_{3}$.Carbonic acid ionizes in water to form $\mathrm{H}+$ and $\mathrm{CO}_{3}^{--}$ions, the concentration of which is measured by resistivity or conductivity. Freshly prepared pure water will rapidly dissolve $\mathrm{CO}_{2}$ from the air and the resulting carbonic acid can lower the $\mathrm{pH}$ as far as 4.5. This can often worry the scientist, but this low $\mathrm{pH}$ does not mean that the water is grossly contaminated, as only a few ppm of dissolved $\mathrm{CO}_{2}$ will cause a $\mathrm{pH}$ of this value. This dissolved gas does not usually cause any problems as it is also present in other reagents being used, but if it must be removed it can only be done by passing through an anion exchange resin and the water must then be protected from contact with the air.

\section{Micro-organisms and Pyrogens}

Some biological contamination of water is caused by the presence of living organisms like algae, bacteria, protozoa, pathogens, microbes, Viruses, Parasites and their eggs (cysts), etc. known collectively known as microorganisms and commonly called 'germs'. These minute living organisms in water are the causes of diseases from dirty water like typhoid fever, dysentery, cholera, gastroenteritis, etc. 
Pyrogens are fever-inducing bacterial endotoxins or other microbial products and are also commonly present in water bodies.. They interfere with most biotechnology and microbiological procedures contaminating the water with DNA and nucleases but are often less relevant to chemistry laboratories.

\section{Primary Adjustment and Corrosion Control of water}

Pure water has a $\mathrm{pH}$ close to 7. It is neither alkaline nor acidic. The range of Sea water can have from 7.5 to 8.4 which are slightly alkaline. Fresh water can have widely ranging $\mathrm{pH}$ values depending on the geology of the drainage basin or aquifer and the influence of contaminant inputs (acid rain). If the water is acidic which is lower than 7limes, soda ash, or sodium hydroxide can be added to raise the $\mathrm{pH}$ during water purification processes.

Lime addition increases the calcium ion concentration, thus raising the water hardness. For highly acidic waters, forced draft degasifies can be an effective way to raise the $\mathrm{pH}$, by stripping dissolved carbon dioxide from the water. Alkaline water helps coagulation and flocculation processes work effectively and also reduces the corrosiveness of water to iron pipes. The ability of water to precipitate calcium carbonate to protect metal surfaces and reduce the toxic metals being dissolved in water is a function of $\mathrm{pH}$, mineral content, temperature, alkalinity and calcium concentration.

\section{Treatments ways for water purification}

Physical characteristics of water include color, odor, and turbidity caused by dissolved or suspended solids. Organic contaminants include dissolved or undissolved volatile organic compounds such as phenols, chlorobenzene, hydrocarbons and dissolved or undissolved non-volatile organic compounds allocated as biological oxygen demand (BOD), chemical oxygen demand (COD), and total organic carbon (TOC)which include carbohydrates, fats, starches etc., Inorganic pollutants may include compounds of trace minerals, sulfides, chlorides, nitrogen and phosphorous.

The various treatments employed for use of water in domestic and industrial purposes can be classified in three ways.

\section{Primary treatment}

2. Secondary treatment

3. Tertiary treatments

In the Primary treatment screening is introduced in the wastewater for removing the suspended large or small particles, settling and skimming the oil from the top layer in the wastewater in the settling tanks. After the primary treatment, the wastewater undergoes secondary treatment, which may be one or more combinations of treatments by activated sludge, filters or lagoons. Secondary treatment is mostly a biological process wherein microorganisms in wastewater convert the non-settle able solids to settle able solids.

\section{Selection of wastewater technologies}

The selection of the treatment technologies depends on the type of the wastewater and the requirements of economy aspect .Highly polluted water having color and containing solid waste is first treated with primary and secondary processes followed by the tertiary water treatment technologies. If the BOD is negligible then a secondary process is not required. If the water is colorless without any solids and is polluted due to inorganic, organic and biological pollutants, then only tertiary water treatment is required. When, groundwater is polluted by toxic metal ions and anions then only tertiary water technologies are required for its treatment. Surface water contaminated by inorganic, organic and biological pollutants requires secondary and tertiary treatment methods. Generally, wastewater is highly polluted and it may be colored with solid waste containing inorganic, organic, biological pollutants, which requires a good hyphenation of primary, secondary and tertiary treatment technologies. The choice of the tertiary water treatment technologies depends on the types of the pollutants present in the water and the optimum selection can be done by considering the above cited discussions. (Than N. C.)

\section{Methods of purifying water Physico-chemical methods}

There are various physicochemical techniques available to remove contaminants like fine solids, micro-organisms and some dissolved inorganic and organic materials, environmental pollutants. There are a variety of techniques available to purify water for the various different uses for which it is required and need for treatment of surface waters and some ground waters for drinking and domestic purposes.

Each of these has different capabilities in terms of which contaminants it will remove effectively and each is subject to its own advantages and disadvantages in terms of cost, ease of use etc. 
No single method is ideal in all circumstances and none is capable of producing the highest purity water. Here we will discuss about the most commonly used technologies and current chemical approaches for water and wastewater treatment may be broadly classified into Distillation,Deionization,,Filtration.,Coagulation and flocculation, Ion exchange and Membrane Separation,Adsorption, and Ultra-light

\section{Distillation}

Distillation is a long established technique of water purification. It has the broadest capabilities and removes the widest spectrum of impurities. It is also unique in that the pure water is removed from the impurities rather than the impurities being removed from the water as is the case with other methods. Raw water is boiled to produce steam which is fed to a condenser where it returns to the liquid state, free of impurity. The impurities remain in the boiler and must be removed periodically, usually by dissolving them in an acid solution. The cooling water supply to the condenser is generally used to feed the boiler with warmed water to increase efficiency. For increased purity, a double still is used where the output from the first stage is then redistilled in the second. The cold water supply enters via a condenser; some of this is fed into a boiler, the remainder falls to drain. The water in the boiler is heated to generate pure steam. The steam condenses in the cold condenser returning the water to liquid state. The pure distillate is then collected in a storage reservoir. The advantages of this techniques are removes all types of contamination except dissolved gases and organic compounds with boiling points below $100^{\circ} \mathrm{C}$. but only $6 \%$ of the water is produced as disllied water . The distilled water must be produced and stored prior to use which increases the chances of it becoming contaminated either by leaching of material from the container or by contact with the air, which may introduce microorganisms.

\section{Deionization}

Also referred to as demineralization or ion exchange, deionization is a chemical process which removes ionic contamination. The feed water is passed over an ion exchange resin where cations react with the resin and release hydrogen ions and the anions release hydroxyl ions. These then combine to produce water molecules. Early deionizers had separate cation and anion resin beds but nowadays these resins are mixed together to form mixed bed deionizers.

As this process continues the resin slowly runs out of available hydrogen and hydroxyl ions and so becomes exhausted. If the resin is not replaced or regenerated the quality of the output would quickly deteriorate

\section{(Strathmann H)}

The principle of deionization using ion exchange resins. Cations and anions in the feed water pass through the resin bed replacing the hydrogen and hydroxyl ions attached to the beads. The released hydrogen and hydroxyl ions then combine to form pure water molecules (Luiz A,)

This method is very effective and low energy consumption for removing inorganic salts from raw water. Very little maintenance required except for resin replacement. Bacteria can grow in the resin if water is not passed through it regularly under pressure. It will not remove bacteria or pyrogens.

\section{Filtration}

A simple filter usually called a sediment filter, with pore size of 20 microns or lower can remove almost all of the suspended matter in muddy water. Also the use of flocculants like Alum is used widely to settle and clear muddy water. Muddy water after passing through a simple filter may be good for drinking, as long as there is no contamination with germs and dissolved chemicals. Three types of filtration are commonly used in water purification .Micro porous filtration uses a membrane of $0.4 \mathrm{~nm}$ pore size which is capable of removing bacteria and particulate matter such as resin fragments from ion exchange columns. Ultra filtration uses a membrane of 1-10nm. This is capable of removing pyrogens andother organic molecules with a molecular weight of $>10,000 \mathrm{Da}$ such as proteins. Activated carbon filters remove chlorine and chloramine by adsorption and are also capable ofre moving some dissolved organics. As the feed water flows through the filtration membranes, water and small molecules pass through the pores whereas larger particles and macromolecules are retainedAdvantages of this process, filtration depends on pore size and effectively removes most colloids, enzymes, micro-organisms particles and endotoxins and activated carbon significantly reduces total organic carbons.but dissolved inorganic and organic substances does not remove by the filtration. Membranes used in this process can be expensive to replace. Activated carbons also sometimes release fines and soluble components into the water body. 


\section{Coagulation and flocculation}

Sedimentation alone is not sufficient to remove all the suspended matter. Slit particles small enough to be in colloidal suspension cannot remove by sedimentation. The process of coagulation is used to remove colloidal particles from water. Coagulation means the treatment of water with reagents so as to remove colloidal and coarse disperses impurities, since colloidal particles of a given substance carry same charges, they are stable and cannot be easily coagulated or consolidate into coarse formations.

It is the first steps in most conventional water purification processes is the addition of chemicals to assist in the removal of particles suspended in water. Particles can be inorganic such as clay and silt or organic such as algae, bacteria, viruses, protozoa and natural organic matter. Inorganic and organic particles contribute to the turbidity and color of water.

The addition of inorganic coagulants like aluminum sulfate (or alum) or ferric salts such as ferric chloride cause various chemical and physical interactions on and among the particles. Within seconds, negative charges on the particles are neutralized by inorganic coagulants. Also within seconds, metal hydroxide precipitates of the iron and aluminum ions begin to form. These precipitates combine into larger particles under natural processes such as Brownian motion and flocculation process.

The term most often used for the amorphous metal hydroxides is "floc." Large, amorphous aluminum and ferric hydroxides adsorb and enmesh particles in suspension and facilitate the removal of particles by subsequent processes of sedimentation and filtration.

Aluminum hydroxides are formed within a fairly narrow $\mathrm{pH}$ range like 5.5 to about 7.7. ferric hydroxides can form over a larger $\mathrm{pH}$ range including $\mathrm{pH}$ levels lower than are effective for alum, typically: 5.0 to 8.5.

In water treatment ferrous sulphate, aluminum sulphate and ferric chloride are used as coagulants. They are used as $5-10 \%$ solution. When a coagulant such as aluminum sulphate is added to water, it hydrolysis according to the equation

$\mathrm{Al}_{2}\left(\mathrm{SO}_{4}\right)_{3}+6 \mathrm{H}_{2} \mathrm{O}$

The acid being formed is neutralized due to water alkalinity

$\mathrm{H}++\mathrm{HCO}_{3}^{-}$----------- $\mathrm{CO}_{2}+\mathrm{H}_{2} \mathrm{O}$

In case of ferrous sulphate the following reaction takes place

$\mathrm{FeSO}_{4}+2 \mathrm{H}_{2} \mathrm{O}$

$\mathrm{H}^{+}{ }_{+} \mathrm{HCO}_{3}^{-}$

$\mathrm{Fe}(\mathrm{OH})_{3}$ acts as the coagulant not the $\mathrm{Fe}(\mathrm{OH})_{2 . T h u s}$ when ferrous iron is used as coagulant the need arises to oxidize it into ferric iron by oxygen dissolved in water.

$\mathrm{H} 2 \mathrm{O}+2 \mathrm{Fe}(\mathrm{OH})_{2}+1 / 2 \mathrm{O}_{2}$

The above reactions show that alkalinity decreases upon coagulation and concentration of free $\mathrm{CO}_{2}$ in water increases. Hence water being treated with coagulants must contain some minimum amount of alkaline substances.

\section{The Water Softening By Ion Exchange Process}

The purification process in which the removal of various metallic elements is through a process known as ion exchange. It is also referred to as water "softening," .Ion exchange utilizes a large tank which is filled with a special, negatively-charged resin. The resin beads serve as bases or sites for the ion exchange to actually take place.(Khan MI)

Ion exchange method is used to soften water by exchanging these elements with sodium ions Sodium is use as a strong acidic cation exchange. Water hardening occurs due to the presence of alkaline earth metals such as calcium and magnesium. These ions prevent soap from forming micelles. A water softener can be made by two or three tanks. The smaller tank contains the sodium or potassium salt used to regenerate the resin media while the larger and taller tank contains the purifying media called a "cation" exchange resin. First, raw water passes through the ion exchange resin media in the large tank. The calcium $(\mathrm{Ca++})$, magnesium $(\mathrm{Mg}++)$, iron $(\mathrm{Fe}++)$, or manganese $(\mathrm{Mn}++)$ ions in the water are typically "exchanged" for sodium $(\mathrm{Na}+)$ or potassium $(\mathrm{K}+)$ ions, which have been temporarily stored in the pores of the resin during the previous regeneration cycle. (Vigneswaran S et al. ) In fact, any contaminant ion of valence positive 2 or greater will be removed in a water softener. As the softener removes hardness minerals from the, sodium or potassium will be given back proportionally 


\section{Water purification by Ultraviolet Light}

UV oxidation is a destruction process that oxidizes organic and explosive constituents in waste water by the addition of strong oxidizers and irradiation with UV light. Ultraviolet disinfection is the first of these technologies used in after water processes remove all chlorine from the water. Two forms of chemical-free disinfection technology are employed to ensure that the purified water remains absolutely and completely free from any sort of microbiological contamination. At this step, the water passes through a special chamber which houses a large ultraviolet light source. This ultraviolet light acts as a powerful sterilizing agent. If any bacteria, viruses, or other microbiological contaminants are present in the water, the ultraviolet light at this particular wavelength destroys the genetic material within these organisms, eliminating the possibility of bacterial or viral reproduction and proliferation. The organisms quickly die and are captured and removed during the profiteering before the reverse osmosis purification process

\section{Conclusion:-}

Clean water is essential for living being, for drinking, cooking and other daily uses purposes like bathing, brushing, washing clothes etc. Undesired chemicals organic and inorganic sals, and biological contaminants are removed from water by advance purification technologies. Water purification also needs of medical, pharmacological, chemical, and industrial applications for potable water. The purification procedure reduces the concentration of contaminants such as suspended particles, parasites, bacteria, algae, viruses, and fungi. By the water filters remove all sorts of available contaminants from water, chlorine is used in swimming pool water that may result in the tanning but you can't drink it since chlorine is not food for the health at all. Chlorine can affect your health in various ways. It can be responsible for difficulty in breathing, chest tightness, skin-eye irritation and other sorts of health problems to count a few. Hence, before drink it, need to ensure its chlorine free.

In modern times, the quality to which water must be purified is typically set by government agencies. Whether set locally, nationally, or internationally, government standards typically set maximum concentrations of harmful contaminants that can be allowed in safe water. In pre-treatment, biological contaminants, chemicals, and other materials are removed from water. The first step in that process is screening, which removes large debris such as sticks and trash from the water to be treated. Screening is used when purifying surface water Pre-treatment of water may include the addition of chemicals to control the growth of bacteria in pipes, tanks and a stage that incorporates sand filtration, which helps suspended solids settle to the bottom of a storage tank.

According to a 2017 report by the United Nations and World Health Organization 2.1 billion people lack access to a safe and reliable drinking water supply at home. Eighty-eight percent of the four billion annual cases of diarrhea reported worldwide have been attributed to a lack of sanitary drinking water. Each year approximately 525,000 children under age five die from diarrhea, the second leading cause of death, and 1.7 million are sickened by diarrheal diseases caused by unsafe water, coupled with inadequate sanitation and hygienemany areas of the world that do not have access to water treatment plants, so they use alternative methods of purification such as boiling, granular activated-carbon filtering, distillation, reverse osmosis, membrane distillation and purified by ultra violet methods.

\section{References:-}

1. Gursimran Singhet.al "Effect of Polluted Surface Water on Groundwater: A Case Study Of Budha Nullah" IOSR Journal of Mechanical and Civil Engineering (IOSR-JMCE) e-ISSN: 2278-1684 Volume 5, Issue 5 (Mar. - Apr. 2013), PP 01-08 .

2. Michelle Thompson A critical review of water purification technology appropriate for developing countries: Northern Ghana as a case study Journal of desalination and water reatment Pages 3487-3493 | received 15 Jan 2014, Accepted 14 Mar 2014, Published online: 27 May 2014

3. American Water Works Association (Ed) (1995) Electrodialysis and electrodialysis reversal: M38. J Am Water Works Assoc 38.

4. Khan MI, et al. (2016) Design of anion exchange membranes and electro dialysis studies for water desalination. Materials 9: 365 .

5. Strathmann H (2010) Electro dialysis, a mature technology with a multitude of new applications. Desalination 264: 268-288.

6. Luiz A, Spencer E, McClure DD, Coster HG, Barton GW, et al. (2018) Membrane selection for the desalination of bio-refinery effluents using electro dialysis. Desalination 428: 1-11. 
7. Sadhana churassia et al. A review on traditional water purification methods used in Rural AreaIndian Journal of Environmental Protection 36(1):43-48 · January 2016 with 3,550 ReadsCite this publication

8. Vigneswaranet et.al Traditional and household water purification methods of rural communities in in developing countries wastewater recycle, reuse and reclamation. Vol. II .

9. Thanh N. C. (1982). Surface Water Filtration for Rural Areas-Guidelines for Design, Construction, Operation and Maintenance. Environmental Sanitation Information Center, Asian Institute of Technology, Bangkok, Thailand.

10. Vigneswaran S. and Visvanathan C. (1995). Water Treatment Processes-Simple Options. Boca Raton: CRC Press. [This book presents simple technological options for advanced treatment levels of drinking water that are be suitable for both developed and developing countries.]

11. Vigneswaran S et al. (1983). Water filtration technologies for developing countries. Environmental Sanitation Review 12, Environmental Sanitation Information Center, Asian Institute of Technology, Bangkok, Thailand. [This is a comprehensive compilation of history and development of water filtration technologies in developing countries.]

12. D. Bhattacharyya, S. Freshour and S. Mawhinney, Nat. Res., 30 (1995) 1949.

13. G. Kreysa and E. Heitz, Principles of Electrochemical Engineering. VCH, Weinheim, New York, (1986).

14. L. Friberg, Cadmium in the Environment, 2nd edition, Chap. 2 CRC Press. Cleveland, Ohio (1974). 